\title{
Heterologous production of active ribonuclease inhibitor in Escherichia coli by redox state control and chaperonin coexpression
}

\author{
Juozas Šiurkus ${ }^{1}$ and Peter Neubauer ${ }^{2^{*}}$
}

\begin{abstract}
Background: Eukaryotic Ribonuclease inhibitor (RI), belonging to the RNH1 family, is distinguished by unique features - a high sensitivity to oxidation due to the large number of reduced cysteins and a high hydrophobicity, which made most production approaches so far unsuccessful or resulted in very low yields. In this work efficient in vivo folding of native RI in the Escherichia coli cytoplasm was obtained by external addition of a reducing agent in tandem with oxygen limitation and overproduction of a molecular chaperonin. After optimisation of the production conditions in the shake flask scale the process was scaled up to high cell densities by applying a glucose limited fed-batch procedure.

Results: RI production in a T7 RNA polymerase based system results in accumulation of aggregated inactive product in inclusion bodies. Combination of addition of the reductant DTT, low production temperature and coexpression of the chaperonin GroELS resulted in high level production of approximately $25 \mathrm{mg} \mathrm{g}^{-1}$ CDW active $\mathrm{RI}$ in E. coli ER2566 pET21b, corresponding to approximately $800 \mathrm{kU} \mathrm{g}^{-1}$ cell wet weight. Further conditional screening under fed-batch-like conditions with the EnBase ${ }^{\circledR}$ technology and scale up into the bioreactor scale resulted in an efficient high cell density glucose and oxygen limited fed-batch process with a final cell dry weight of $25 \mathrm{~g} \mathrm{~L}^{-1}$ and a total Rl yield of app. $625 \mathrm{mg} \mathrm{L}^{-1}$ (volumetric activity of $80,000 \mathrm{kU} \mathrm{L}^{-1}$ ). The E. coli based production constructs showed a very high robustness. The recombinant culture maintained its productivity despite the combination of the toxic growth conditions, the substrate limited production mode in tandem with a high level expression of several recombinant proteins, the set of molecular chaperonins and the target protein (RI).

Conclusions: High level production of active RI in E. coli in a T7 RNA polymerase expression system depends on the following factors: (i) addition of a reducing agent, (ii) low production temperature, (iii) oxygen limitation, and (iii) co-overexpression of the chaperonin GroELS. The study indicates the strength of applying fed-batch cultivation techniques for the efficient optimisation of production factors already at the screening stage for fast and straight forward bioprocess development even for target proteins which show a complex folding behaviour. In our case none of the approaches alone would have resulted in significant accumulation of active Rl.
\end{abstract}

\section{Background}

E. coli is a favorable host for recombinant heterologous protein production. The robustness of this microorganism, fast and simple cultivation, easy genetical manipulation, the enormous amounts of available physiological data and molecular biology tools are key reasons for its widespread use. Despite these positive general

\footnotetext{
* Correspondence: peter.neubauer@tu-berlin.de

${ }^{2}$ Chair of Bioprocess Engineering, Department of Biotechnology, Technische Universität Berlin, Ackerstr. 71-76, D-13355 Berlin, Germany

Full list of author information is available at the end of the article
}

characteristics, protein aggregation and/or improper folding are major obstacles which often lead to reduced functional product yields. Many examples indicate the limited capacity of the natural E. coli protein folding machinery for a high level accumulation of heterlologous proteins with features wich are not usual for the hosts protein portfolio. Examples are proteins with multiple disulfide bonds, very large proteins, proteins with a high hydrophobicity, and proteins with natural glycosylation. However, target specific engineering approaches and process optimisation can lead to success. In the

\section{Biomed Central}


meanwhile there exists an extensive toolbox of elements which overcome natural limitations of the $E$. coli system, such as vectors for coexpression of rare tRNAs, chaperons and foldases, hosts and vectors with improved disulfide oxidation and isomerisation characteristics, newly designed secretion tools, and hosts for superior expression of membrane proteins [1-3]. Even tools for modulation the glycoylation pattern of proteins seems to become a future option $[4,5]$.

Due to their therapeutic importance the production of disulfide stabilised proteins has been a major research focus in the past. This research gave the general impression that the cytoplasm of $E$. coli is a reducing compartment and thus the production of proteins with reduced cysteines should be granted. Hyperoxia and oxydation stress are important factors in connection with protein folding in Eukaryotes (e.g. see recent review by [6]), but have been largely neglected for recombinant protein production in E. coli. Although oxidative damage of proteins by carbonylation in E. coli has been extensively studied, it has been barely considered in connection with heterologous protein expression. One milestone publication in this aspect is the effect of the dissolved oxygen level on the carbonylation level and activity of human interferon $\gamma$ [7].

In the present study we show at the example of a protein of the ribonuclease inhibitor (RI) family, that the redox conditions in the cytoplasm are an important target for process optimisation if the aim is the production of soluble and active product.

Proteic RIs are a family of highly conserved proteins. The conservation of the amino acid sequence between different hosts, such as pig, cow, rat, mouse, sheep and human is as high as nearly $70 \%$ [8]. All eukaryotic ribonuclease inhibitors share the following characteristics: (i) a high content of reduced cysteins (30-32 residues, $7 \%$ of total amino acids), and (ii) a core composed of 15-16 repeated hydrophobic leucine rich motives $[8,9]$. Due to these features recombinant production of eukaryotic ribonuclease inhibitors has been a challenge. Earlier production trials of human and porcine RI in $E$. coli resulted in low functional yields and major aggregation [10,11]. For example the yield of functional porcine RI in E. coli was as low as $10 \mathrm{mg}$ $\mathrm{L}^{-1}[10]$ and in Sacharomyces cerevisiae $0.2 \mathrm{mg} \mathrm{g}^{-1}$ wet weight [12]. Recently we reported production of soluble and functional RI as a fusion to maltose binding protein (MBP) in E. coli [13] with a relatively high yield of $39 \mathrm{mg} \mathrm{g}^{-1}$ cell dry weight which could be realised in a medium-density fed-batch process with a final yield of app. $800 \mathrm{mg} \mathrm{L}^{-1}$ of MBP-RI fusion protein, and correspondingly $425 \mathrm{mg} \mathrm{L}^{-1}$ of RI. Similar amounts of functional RI per cell unit from N-terminal fusion proteins were recently obtained by Guo et al.
[14], however the authors did not try to maximize the volumetric yield.

Fusion proteins have the disadvantage that an extra proteolytic processing step is needed to obtain the authentic RI, which would be a limitation for industrial scale production. Also, although the tagged protein was soluble, the $\sim 40 \mathrm{kDa} \mathrm{MBP}$ fusion partner had a negative impact on the RI specific activity. Therefore in a next study we intended to directly produce almost authentic RI. Therefore we applied two strategies: (i) a cytoplasmic construct with an N-terminal His tag and (ii) a periplasmic construct with a secretion signal which would be removed during the transport of RI into the periplasm [15]. Surprisingly, we only succeeded in high yields of soluble and active RI with the cytoplasmic construct, and only if the reductant dithiothreitol (DTT) was added to the cultivation medium. The same production approach also improved the periplasmic yield of RI. However unexpectedly, the yield of active and soluble RI was higher with the cytoplasmic compared to the periplasmic expression constructs. After further comprehensive optimisation, including different vector constructs and expression principles, the best yield of $320 \mathrm{mg} \mathrm{L}^{-1}$ of active $\mathrm{His}_{6}$-RI was obtained, by combination of the addition of DTT with a low cultivation temperature $\left(22^{\circ}\right.$ C) and reduced aeration $\left(\mathrm{pO}_{2}\right.$ close to zero) [15].

In the present study we aimed to further increase the cytoplasmic yield of native RI, i.e. without any tag, by applying the very strong routinely used T7 RNA polymerase controlled expression system. Surprisingly, the tested ER2566 (E. coli B-strain) pET21b constructs behaved totally different compared to the earlier tested constructs ( $E$. coli $\mathrm{K}-12$, plasmids with a lac-derived promoter). DTT did not provide a positive effect on the yield of functional RI, possibly due to the imbalance between very strong protein synthesis and slow folding. The problem was solved by co-overexpression of the GroELS chaperonine. The yield of RI finally could be maximized by combining the sequential induction of GroELS and RI with a delayed addition of DTT and the maintenance or a low level of dissolved oxygen. This process strategy also was successful in a bioreactor under fed-batch process conditions with a final cell dry weight of $25 \mathrm{~g} \mathrm{~L}^{-1}$ and a volumetric yield of $625 \mathrm{mg} \mathrm{L}^{-1}$ of soluble and highly active RI.

\section{Results}

In the present study we were interested to further develop the RI process for cytoplasmic production. Therefore we selected the widely used strong T7 RNA polymerase based expression system based on the vector pET21b and the E. coli B strain ER2566 as a production host. In the first set of production trails we applied supplementation with DTT and low production 
temperature, as those have been key parameters for active RI production in our previous approach [15]. Surprisingly, contrary to our expectations, DTT did not positively affect soluble accumulation, nor resulted in any higher RI activity in shake flask cultures of $E$. coli ER2566 pET21bRI, independent from the postinduction temperature and DTT addition time (Figures 1 and 2, also see SDS-Page gels in Additional file 1). Despite, a large amount of RI accumulated in inclusion bodies (Additional file 1).

A major difference between the previous and the actual expression systems is the strength of transcription. Previously we used a lac derived promoter, but here we used the T7 RNA polymerase based promoter system. The new system supports a very high rate of product synthesis corresponding to more than $60 \mathrm{mg}$ $\mathrm{gCDW}^{-1}$ (Figure 2 and Additional file 1) even at the low production temperature. Thus we assumed that the aggregation of RI could be due to the overloading of the cellular folding machinery by the hydrophobic and slowly folding RI. To test this hypothesis we coexpressed the chaperon systems DnaKJE and GroELS in tandem with RI.

While co-overexpression of DnaKJE did not provide any significant improvement in our case, coexpression of GroELS resulted in an increased RI solubility (Figure 2, Additional files 2 and 3) and activity (Figure 1). This positive effect was stronger at a lower postinduction temperature, but the best yield was obtained when DTT was added. The combination of GroELS and DTT resulted in $30-55 \%$ improvement of the accumulation of soluble RI (Figure 2 and Additional file 3) and a 1.5 to 2 fold increase in RI activity (Figure 1) compared to the trials without DTT. The best result was obtained when DTT was added two hours after RI induction in combination with a lower postinduction temperature of 30 or $22^{\circ} \mathrm{C}$ (Figures 1 and 2).

Remarkably, although the highest volumetric activity was obtained with the delayed addition of DTT, the highest activity per cell was obtained when DTT was added at the time of RI induction. In comparison to the processes without DTT the RI activity per cell increased

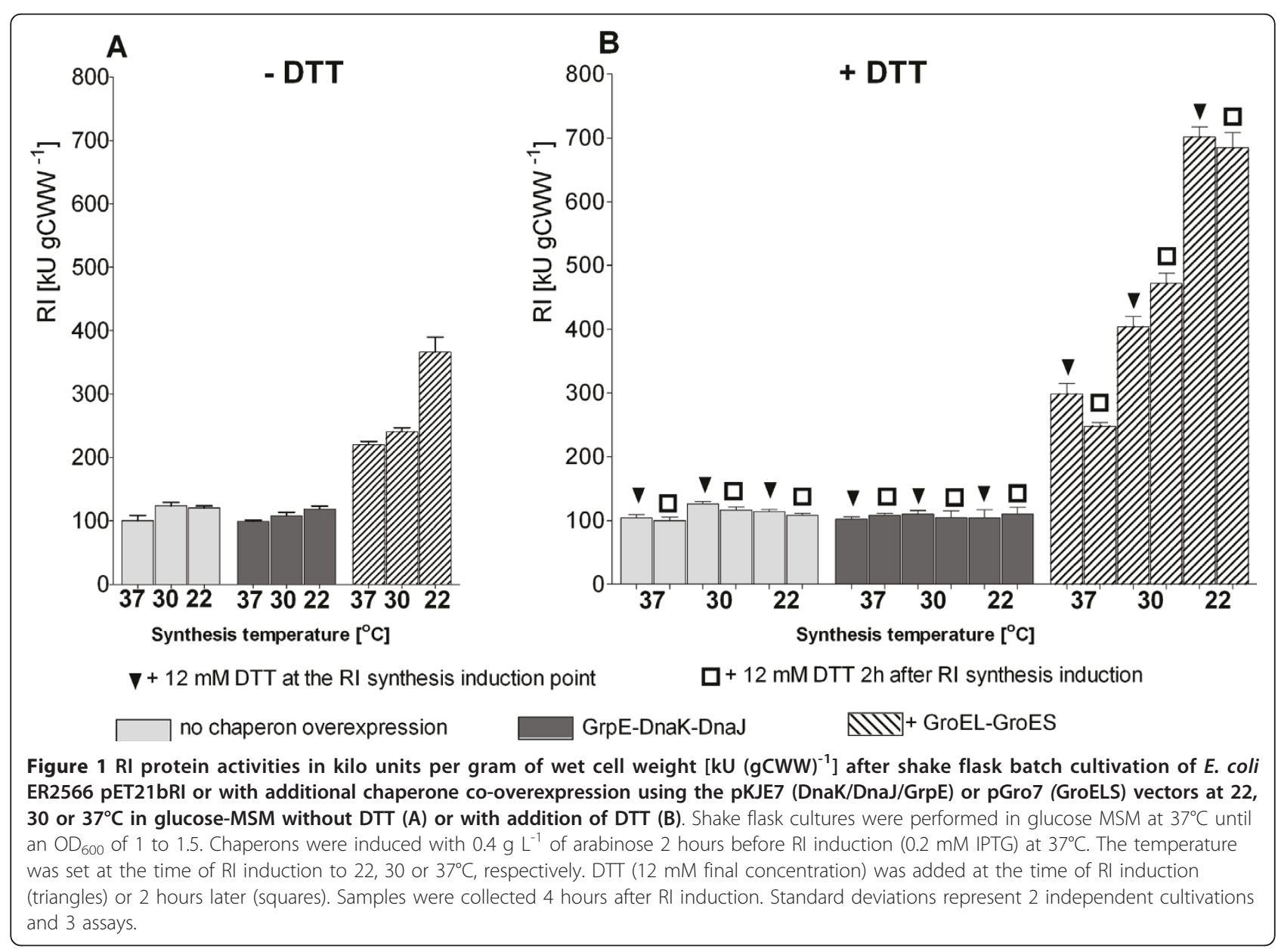




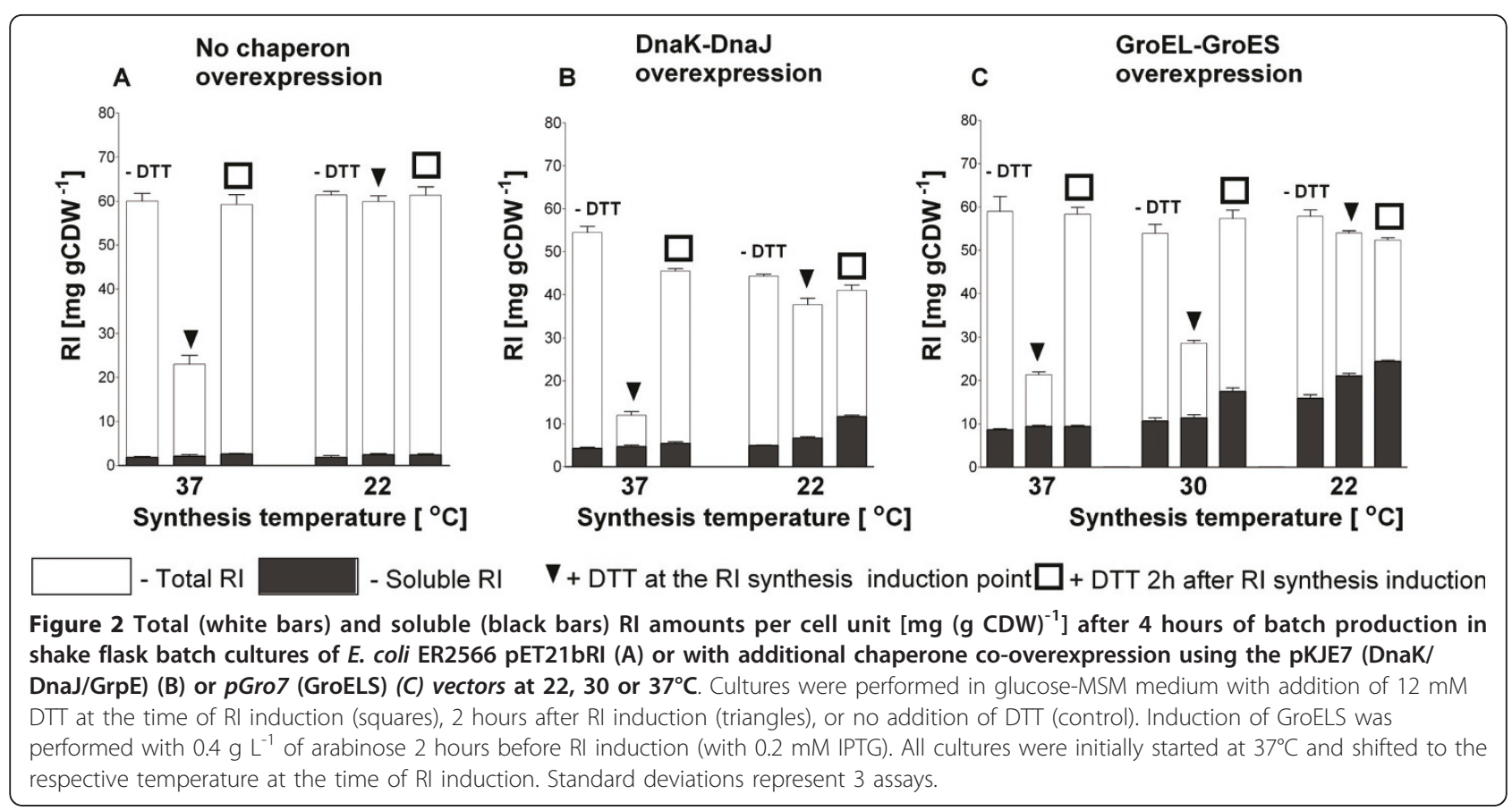

by $90 \%$ when DTT was added at the time of RI induction, but only by $70 \%$ in the case of delayed DTT addition (Figure 1).

Interestingly, the combination of DTT and DnaKJE overproduction did only increase the solubility of RI, but the product was principally inactive (Figures 1, 2 and Additional file 2).

In conclusion, (i) the highest activity of RI per cell unit was obtained with a postinduction temperature of $22^{\circ} \mathrm{C}$ co-expression of GroELS and addition of DTT. (ii)

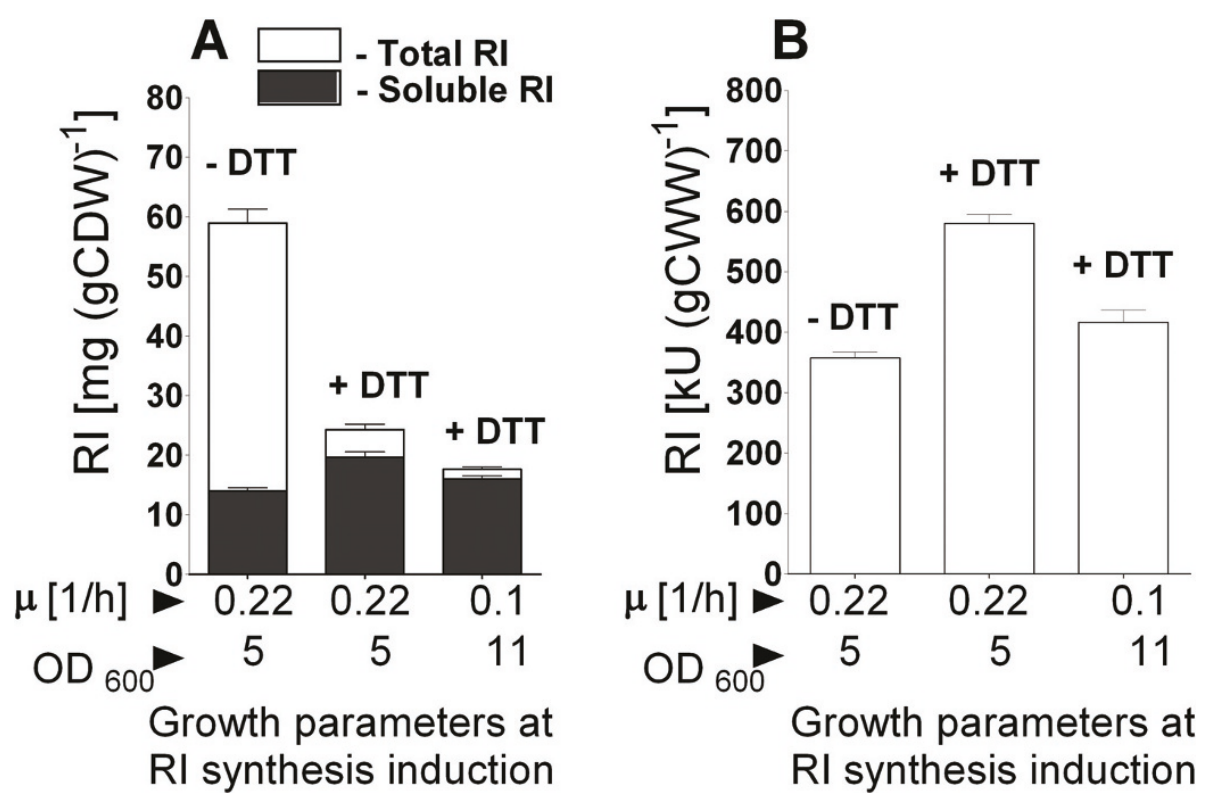

Figure 3 RI protein yields after shake flask EnBase fed-batch cultivation of E. coli ER2566 pET21bRI pGro7 without DTT (-DTT) or with addition of $12 \mathrm{mM}$ of DTT 2 hours after induction of RI (+DTT). Total (white bars) and soluble (black bars) RI amounts in milligrams per gram of dry cell weight [mg ( $\left.\mathrm{g} \mathrm{CDW})^{-1}\right](\mathrm{A})$ and Rl activities in normalised crude extracts in kilo units per gram of wet cell weight [kU (g CWW) $\left.{ }^{-1}\right]$ (B) 4 hours after RI induction. The amounts of target protein in (A) were determined from scanned SDS-PAGE gel images as described in material and Methods. Standard deviations represent RI amounts from 3 assays. 
The delayed DTT addition was preferred in the next set of experiments, as it seemed to be less detrimental to the culture viability.

\section{Fed-batch process in shake flasks}

As previously, prior to the bioreactor experiments the fed-batch procedure was basically tested and optimised in shake flasks by applying the EnBase cultivation technique [16]. RI synthesis was induced 2 hours after induction of GroELS by addition of $0.2 \mathrm{mM}$ IPTG, at the fed-batch cultivation mode at $\mathrm{OD}_{600} \approx 5(\mu \approx 0.22$ $\mathrm{h}^{-1}$ ) or $\mathrm{OD}_{600} \approx 11\left(\mu \approx 0.10 \mathrm{~h}^{-1}\right)$, respectively. Analogical to the batch processes, the cultivation medium was supplemented with DTT at the time of RI induction or 2 hours after induction. RI production was performed at $22^{\circ} \mathrm{C}$ for 4 hours. The effect of DTT on the production of RI and during co-expression of GroELS was evaluated by comparing the results to a culture without DTT addition.

Interestingly, independent from the cell density at the time of RI induction and in difference to the batch shake flask cultures described above, DTT addition at the time of RI induction had a negative effect on the accumulation of RI, even at the low synthesis temperature (results not shown). In contrast, delayed DTT addition was better, but still the total amount of RI decreased to about $50 \%$ in comparison to the fed-batch process without DTT (Figure 3, Additional file 4). However, despite the negative effect of DTT on the total amount of RI per cell (soluble and insoluble fractions), the yield of soluble and active RI per cell was doubled and the final volumetric activity was even five-fold improved compared to the previous batch experiments. Interestingly, the total amount of RI was higher at early induction $\left(\mathrm{OD}_{600} \approx 5\right)$ compared to late induction $\left(\mathrm{OD}_{600} \approx 11\right)$, indicating that the balance of synthesis rate and folding is an important optimisation parameter (Figure 3).

From this part we conclude that the most appropriate fed-batch growth conditions for RI production with GroELS and DTT would be to perform the induction of RI at a specific growth rate $\mu$ between 0.1 and $0.22 \mathrm{~h}^{-1}$. Preferably, DTT should be added 1 to 2 hours after RI induction.

\section{Bioreactor process}

By taking the previous results into account, the batch and fed-batch RI production processes in the stirred bioreactor with the presence of DTT and GroELS overexpression were designed. Additionally, as a reference culture, also an RI production process without DTT was performed.

RI induction in a glucose limited fed-batch under substrate limitation in the stirred bioreactor cultures was performed at optical densities of app. 20 and 38. It was decided to maintain the specific growth rate in all fedbatch cultures at $\mu \approx 0.22 \pm 0.03 \mathrm{~h}^{-1}$ by an exponential addition rate of the glucose feed solution. As a control also a batch culture was performed with induction of RI at an $\mathrm{OD}_{600}$ of $5\left(\mu \approx 0.5 \mathrm{~h}^{-1}\right)$. In all processes GroELS overexpression was induced 2 hours before induction of the target protein at $37^{\circ} \mathrm{C}$ (Figure 4) and the temperature was decreased to $22^{\circ} \mathrm{C}$ at the time of RI induction. Interestingly, in difference to our previously published fed-batch process with the lac-derived promoter system and the E. coli $\mathrm{K}-12$ strain [15], in the current cultivations with coexpression of GroELS, the growth of the cultures was not completely inhibited by the addition of DTT, but the cells grew still with $\mu \approx 0.15 \mathrm{~h}^{-1}$ until the end (Figure 4).

By taking the previous study into account, the bioreactor cultivation medium was supplemented with DTT at two different modes; (i) a single DTT pulse addition starting 2 hours after RI induction and (ii) repeated DTT pulses, analogical starting 2 hours after RI synthesis induction. In all bioreactor processes, the air flow was reduced at the DTT addition point, from 30 to $3-5 \mathrm{~L} \mathrm{~min}^{-1}$ to maintain the dissolved oxygen concentration in the cultivation medium close to $0 \%$. The stirrer speed was kept the same as before induction (Figure 4).

In agreement with the results from the small-scale study, also in the bioreactor fed-batch processes DTT decreased the accumulation of total RI by 30 to $40 \%$ compared to the processes without DTT (Figure 5, Additional file 5). However, despite the negative effect of DTT on the total yield of RI per cell, independently from cultivation mode, DTT improved the soluble amount of RI by 30 to $35 \%$. The RI activity in cultures without DTT was very poor, but a $3.2-3.9$ fold overall improvement of the activity per cell was obtained with repeated DTT addition compared to the processes without DTT. Interestingly, in contrast to the previously described E. coli $\mathrm{K}-12$ process also a single DTT addition caused a good improvement of the RI activity with the new construct (2.2-2.8 fold overall improvement, Figure 5). This was surprising, as the DTT oxidation pattern in this process was similar as in the previously described process of E. coli RV308 K-12 [15]. After 3 hours of RI production at the micro-aerobic conditions only 40 to $50 \%$ of reduced DTT was detected in the bioreactor medium, and 85 to $90 \%$ in a shake flasks process, respectively.

Like in the shake flaks the highest amount of RI per cell unit $\left(\approx 60 \mathrm{mg} \mathrm{gCDW}^{-1}\right)$ was achieved in the batch bioreactor without DTT (Figure 5, Additional file 5). The RI amount per cell was approximately $15-30 \%$ lower during fed-batch operations, depending on the 

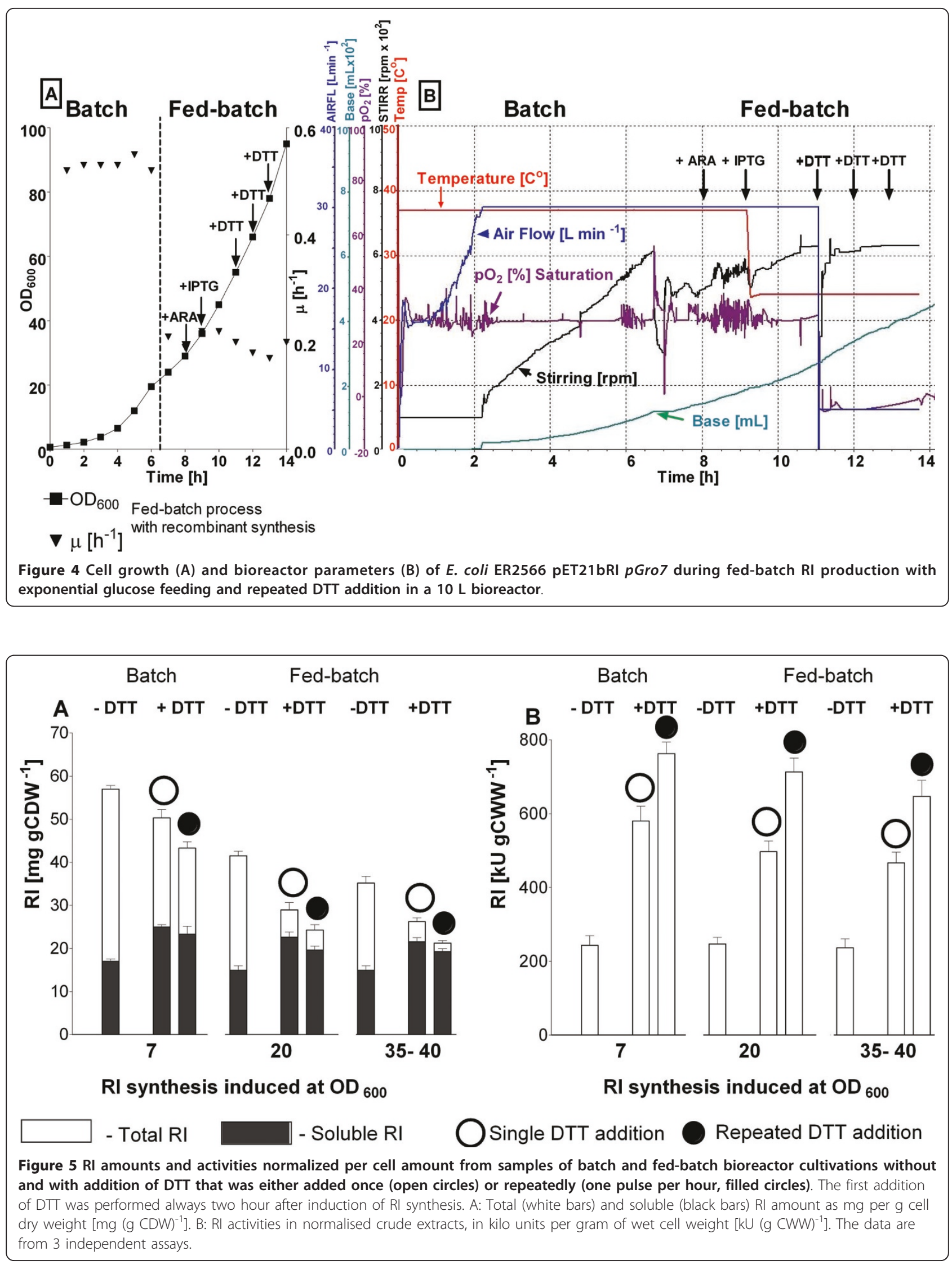
cell density at the synthesis induction point (Figure 5, Additional file 5).

Although the RI activity per cell unit was slightly lower in the fed-batch cultures compared to the batch cultures, the volumetric yield of active RI was much higher, especially when RI synthesis was induced at higher $\mathrm{OD}_{600}$. In this case final optical densities of 90 to 95 were reached, corresponding to 23 to 25 g cell dry weight per litre. The fed-batch process with repeated DTT addition yielded $625 \mathrm{mg} \mathrm{L}^{-1}$ of RI corresponding to a volumetric activity of $\sim 80,000 \mathrm{kU} \mathrm{L}^{-1}$.

\section{Discussion}

In this work we established an efficient recombinant process for Ribonuclease inhibitor (RI) production, resulting in $625 \mathrm{mg} \mathrm{L}^{-1}$ of active product with the authentic amino acid sequence. Previously we had improved cytoplasmic and periplasmic folding by either screening for a functioning fusion partner [13] or by controlling the redox situation by external addition of DTT [15] in the E. coli RV308 K-12 strain.

Surprisingly, the earlier published approach for cytoplasmic expression of authentic RI only worked in the E. coli $\mathrm{K}-12$ system with a $\mathrm{P}_{\text {lac }}$ promoter, but not in the strong T7 RNA polymerase based expression platform. In the T7 RNA polymerase system all product aggregated, possibly due to the high synthesis rate of RI and thus it outcompetes cellular folding factors. This hypothesis seems to be confirmed by the significant improvement of active RI by co-production of the GroELS chaperonins.

Our attempts to produce RI with chaperons also gave interesting and unexpected results, once more demonstrating the unpredictable effects of chaperon coproduction on the soluble accumulation of target proteins. In our case the most promising DnaKJE chaperone system only resulted in a improvement of RI folding, reflected by increase in the solubility of RI, but the product showed no activity. In contrast, co-production of GroELS had a large positive effect on the soluble accumulation and activity of RI. The best results were achieved at a low production temperature (see Results section Figures 1, 2). Although GroELS co-production has been successfully applied for many recombinant proteins (see recent review by Kolaj et al. [17]), our success was not granted, because there are many reports where GroELS overproduction failed to solubilise or to correctly fold proteins of interest [18-21]. The DnaKJE chaperone system is acting in the early stages of the folding pathway. Thus it possibly stabilizes nascent RI molecules by binding to the hydrophobic patches that stipulates solubility increase, but cannot facilitate complete formation of the native RI horse shoe structure because this would require additional more sophisticated folding. Interestingly, a closer look to the gels shows that DnaK is barely aggregating in tandem with RI, but DnaJ follows RI into the insoluble protein fraction, meaning that DnaJ and RI interact very strongly (Additional file 2). Possibly DnaJ remains bound also in the soluble protein fraction and prevents RI interaction with substrate during the activity assay.

The maximum RI activity and amount in the soluble fraction was achieved in all RI/GroELS co-production experiments at a low post-induction temperature, which fits well with the hypothesis that the cell machinery is easily overloaded by a high production of RI. It may be possible that the increase of solubility and activity of RI, having a size of $49 \mathrm{kD}$, was obtained by full encapsulation of the target protein within the GroEL barrel, which was stronger expressed in all cases compared to RI (see Figures 3, 4 and 7). Such a shielding RI from the environment may be advantageous to protect it from inactivation by oxidation and may be an explanation for the higher robustness of the GroELS coexpression process for the procedure of when and how DTT is added compared to the previous process where RI was simply expressed in the cytoplasm of E. coli.

Interestingly, in all shake flaks batch production experiments, the tandem of RI synthesis induction and DTT addition had a negative effect on the total amount of RI, especially when the production was carried out at higher temperatures. In our opinion, the combination of DTT toxicity, strong RI induction and high production temperature was a strong physiological stress, which drastically diminished cellular resources required for high level RI accumulation. For many other examples such impact of strong induction on cellular growth and recombinant production has been described before. In case of aggregation of the target protein a heat shock like response is induced which leads to accumulation of chaperones and proteases [22-24], changes in cellular respiration $[25,26]$ and even ribosome destruction and loss of viability $[27,28]$. Interestingly however, somehow the cells in our case were capable to cope with the physiological stress. They maintain RI productivity when the temperature was decreased to $22^{\circ} \mathrm{C}$ and/or DTT was added only two hours after induction of RI.

Despite its growth inhibiting effect DTT had a positive effect on the solubility and activity of RI during production in shake flasks with GroELS coproduction, possibly by preventing oxidation of cysteins. These data are in good agreement with our previous data of RI production in the E. coli K-12 strain, were the dependency of the RI activity on the DTT concentration was demonstrated [15].

Before development of a high cell density bioreactorscale fed-batch process it was important to test productivity and target protein folding capabilities of the 
ER2566 pET21bRI pGro7 construct under substrate limitation. As previously [13], we applied the EnBase fedbatch technique in parallel shake flask trials. We considered that strong co-overexpression of the target protein and the GroELS chaperonin, as well as other factors connected to the recombinant vectors, e.g. expression of the two antibiotic resistance genes, could withdraw critical amount of energy recourses leading to a loss of production capacity under glucose limited cultivation conditions, especially in the presence of toxic DTT. According to this expectation the combination of substrate limitation and DTT decreased the total amount of RI, but the amount of soluble and active RI was even slightly increased. This was also confirmed in bioreactor experiments which were performed by the same principle but at much higher cell densities.

Interestingly, in contrary to the previous study, in EnBase cultures even after a single pulse of DTT, chaperon-mediated RI folding resulted in a twofold higher RI activity compared to the reference process without DTT. However in the bioreactor, despite applying a very low aeration rate, DTT was fast oxidised and thus repeated addition of DTT was absolutely necessary for obtaining a high final product concentration, like in our previous study [15]. However, remarkably the negative effect of DTT oxidation on the folding of RI was not as strong as in the earlier production system, possibly by the shielding effect of GroELS.

In difference to the earlier published process with the $\mathrm{K}-12$ strain and the lac promoter system, the cell growth showed a high robustness of the ER2566 pET21bRI pGro7 clone to the process conditions. After induction cell growth did not cease, but the culture was still growing with a specific growth rate of $\mu \approx 0.15 \mathrm{~h}^{-1}$ until the end of the cultivation and was completely consuming the carbon source. This indicates metabolic activity and recombinant productivity at the very high cell densities even after repeated pulses of DTT and a final DTT concentration over $3.5 \mathrm{~g} \mathrm{~L}^{-1}$. We consider, that cooverexpression of GroELS stipulated such cell robustness against very harsh conditions by saving cellular host proteins which were affected by the high DTT concentrations.

\section{Conclusions}

In this work a unique production strategy for RI was established which is based on co-overexpression of GroELS chaperonins, low production temperature and maintenance of reducing conditions. GroELS possibly shields the very slowly folding RI from the environment and thus prevents aggregation of this hydrophobic protein. Also the reducing environment in the GroEL barrel may avoid oxidation of the cysteins of RI. We believe that our strategies may be also important for the folding of other slow folding aggregation-prone proteins. Interestingly, coexpression of GroELS makes the cells more resistant to the toxicity of DTT. This is an interesting aspect that needs further functional investigation.

\section{Methods}

\section{Expression strain preparation}

The E. coli B strain ER2566 (New England Biolabs) was transformed with the plasmid pET21b-RI and was plated on LB agar with ampicillin $\left(100 \mu \mathrm{g} \mathrm{mL} \mathrm{L}^{-1}\right)$. The expression strain E. coli ER2566 pET21b-RI was co-transformed with the vectors pGro7 and pKJE7 (Takara Bio Inc) respectively, carrying the genes for the GroELGroES and DnaK-DnaJ chaperone systems. Transformants with both plasmids were plated on LB agar containing ampicillin $\left(100 \mu \mathrm{g} \mathrm{mL}^{-1}\right)$ and chloramphenicol $\left(30 \mu \mathrm{g} \mathrm{mL}^{-1}\right)$. Both transformations were based on the calcium temperature shock method. Glycerol cell stocks were produced after $8 \mathrm{~h}$ of cultivation of the transformants in liquid LB medium with the required antibiotics at $37^{\circ} \mathrm{C}$ and $220 \mathrm{rpm}$. A $50 \%$ sterile glycerol solution was used to produce $25 \%$ glycerol stock cell stocks which were aliquoted in Eppendorf tubes and stored at $-70^{\circ} \mathrm{C}$.

\section{Cultivation media}

Transformations and plasmid propagations were performed on solid and liquid LB medium containing Bacto-Tryptone $\left(10 \mathrm{~g} \mathrm{~L}^{-1}\right)$, Bacto-yeast extract $\left(5 \mathrm{~g} \mathrm{~L}^{-1}\right)$, $\mathrm{NaCl}\left(10 \mathrm{~g} \mathrm{~L}^{-1}\right)$, and for solid medium $15 \mathrm{~g} \mathrm{~L}^{-1}$ bacto agar, as well as the required antibiotics. Fed-batch and batch cultivations were performed in glucose-based mineral salt medium (MSM) with the following composition (per litre): $\mathrm{Na}_{2} \mathrm{SO}_{4} 2 \mathrm{~g},\left(\mathrm{NH}_{4}\right)_{2} \mathrm{SO}_{4} 2.68 \mathrm{~g}, \mathrm{NH}_{4} \mathrm{Cl}$ $0.5 \mathrm{~g}, \mathrm{KHPO}_{4} 14.6 \mathrm{~g}, \mathrm{NaH}_{2} \mathrm{PO}_{4} \times \mathrm{H}_{2} \mathrm{O} 3.6 \mathrm{~g},\left(\mathrm{NH}_{4}\right)_{2}-\mathrm{H}-$ citrate $1.0 \mathrm{~g}$, and glucose 10 to $15 \mathrm{~g}$. $\mathrm{NaOH}(40 \%)$ was used to adjust $\mathrm{pH}$ to 7.0 prior to the heat sterilisation. Additionally, before cultivation the mineral salt medium was supplemented with the following sterile solutions: 3 $\mathrm{mL} \mathrm{L}^{-1}$ of $(1 \mathrm{M}) \mathrm{MgSO}_{4}$ and $2 \mathrm{~mL} \mathrm{~L}^{-1}$ of trace element solution with the following composition (per litre): $\mathrm{CaCl}_{2} \times{ }_{2} \mathrm{H}_{2} \mathrm{O} 0.5 \mathrm{~g}, \mathrm{ZnSO}_{4} \times 7 \mathrm{H}_{2} \mathrm{O} 0.18 \mathrm{~g}, \mathrm{MnSO}_{4} \times$ $\mathrm{H}_{2} \mathrm{O} 0.1 \mathrm{~g}, \mathrm{Na}_{2}$-EDTA $20.1 \mathrm{~g}, \mathrm{FeCl}_{3} \times 6 \mathrm{H}_{2} \mathrm{O} 16.7 \mathrm{~g}$, $\mathrm{CuSO}_{4} \times 5 \mathrm{H}_{2} \mathrm{O} 0.16 \mathrm{~g}, \mathrm{CoCl}_{2} \times 6 \mathrm{H}_{2} \mathrm{O} 0.18$ g; as well as $100 \mu \mathrm{L} \mathrm{L}^{-1}$ of thiamine hydrochloride $(1 \mathrm{M}), 1 \mathrm{~mL} \mathrm{~L}^{-1}$ of ampicilin $\left(100 \mathrm{mg} \mathrm{mL}^{-1}\right)$ and $1 \mathrm{~mL} \mathrm{~L}^{-1}$ of chrolamphenicol $\left(30 \mathrm{mg} \mathrm{mL}^{-1}\right)$. The feeding solution for fedbatch cultivations was based on fully formulated MSM with the required antibiotics and $550 \mathrm{~g} \mathrm{~L}^{-1}$ of glucose.

\section{Batch mode cultivations and recombinant protein synthesis in shake flasks}

The inoculums for batch protein production in the shake flasks were prepared by overnight cultivation of 
the selected clone in $500 \mathrm{~mL}$ shake flaks with $50 \mathrm{ml}$ of MSM medium containing $10 \mathrm{~g} \mathrm{~L}^{-1}$ of glucose at $37^{\circ} \mathrm{C}$. For protein production $2 \mathrm{~mL}$ of the corresponding inoculum culture was transferred to fresh mineral salt medium containing $10 \mathrm{~g} \mathrm{~L}^{-1}$ of glucose to a final volume of $200 \mathrm{~mL}$ in $1 \mathrm{~L}$ baffled Erlenmeyer shake flasks. Cultures were cultivated at $37^{\circ} \mathrm{C}$ and $220 \mathrm{rpm}$ until they reached the chaperon over-expression induction point, corresponding to a cell density of $\mathrm{OD}_{600} \approx 0.5 \pm 0.05$ ( $\mu$ $=0.42 \pm 0.05 \mathrm{~h}^{-1}$ ). Induction was performed with of 0.4 $\mathrm{g} \mathrm{L}^{-1}$ of arabinose. RI was induced 2 hours after chaperon induction with $0.2 \mathrm{mM}$ IPTG. The reducing agent dithiothreitol (DTT) was added to expression cultures as a dry powder to the cultivation medium at the RI induction point or 2 hours after RI induction to achieve a final concentration of $12 \mathrm{mM}$. The temperature was changed at the RI induction point to 22,30 , or $37^{\circ} \mathrm{C}$ and the culture was continued for 4 hours at $220 \mathrm{rpm}$.

\section{Fed-batch mode cultivations and recombinant protein synthesis in shake flasks}

The EnBase ${ }^{\circledR}$ technology based fed-batch shake flask cultivations were performed in $1 \mathrm{~L}$ baffled Erlenmeyer flasks in $200 \mathrm{~mL}$ of MSM as described before by Siurkus et al. [13]. In all experiments the cells were cultivated at the substrate limited mode, generated with $12 \mathrm{AGU} \mathrm{L}^{-1}$ of glucoamylase in the medium. GroELS and RI were induced at the two cell densities, which corresponded to the following optical densities and specific growth rates: (1) $\mathrm{OD}_{600}$ [GroELS] $\approx 3.0$ and $\mu$ [GroELS] $\approx 0.22 \mathrm{~h}^{-1}$; $\mathrm{OD}_{600}[\mathrm{RI}] \approx 5.0 \pm 0.2$ and $\mu[\mathrm{RI}] \approx 0.22 \mathrm{~h}^{-1} ;(2) \mathrm{OD}_{600}$ $[$ GroELS $] \approx 9$ and $\mu[$ GroELS $] \approx 0.15 \mathrm{~h}^{-1}, \mathrm{OD}_{600}[\mathrm{RI}] \approx$ $11, \mu[R I] \approx 0.1 \mathrm{~h}^{-1}$. With this procedure GroELS synthesis was induced with $0.4 \mathrm{~g} \mathrm{~L}^{-1}$ of arabinose 2 hours before RI. The cultivation temperature and agitation parameters after chaperon induction were maintained at $37^{\circ} \mathrm{C}, 180 \mathrm{rpm}$. RI induction was performed with 0.2 $\mathrm{mM}$ of IPTG, the temperature was shifted to $22^{\circ} \mathrm{C}$, and the culture was continued for $4 \mathrm{~h}$ at a shaking speed of $180 \mathrm{rpm}$. DTT was added as a dry powder at the RI induction point or 2 hours after RI induction to a final concentration of $12 \mathrm{mM}$.

\section{Bioreactor processes}

Batch and fed-batch cultures were performed in a $15 \mathrm{~L}$ Biostat C bioreactor (B. Braun Biotech, Melsungen, Germany) with an initial cultivation volume of 8 litres. The initial culture parameters as follows: the $\mathrm{pO}_{2}$ was maintaind at $30 \%$ by adapting the stirrer rate and automatic regulation of the air flow (from 0 to 30 liters per min), $\mathrm{pH}$ was controlled at $7.0 \pm 0.1$ by addition of $\mathrm{NH}_{4} \mathrm{OH}$ (25\%) or $\mathrm{H}_{3} \mathrm{PO}_{4}(2 \mathrm{M})$. During all bioreactor processes the growth temperature before and after GroELS induction was maintained at $37^{\circ} \mathrm{C}$. The temperature in all processes was down-regulated from 37 to $22^{\circ} \mathrm{C}$ at the RI induction point. A $0.65 \mathrm{M}$ DTT stock solution in MSM was added to the culture 2 hours after RI induction to achieve a final concentration of $12 \mathrm{mM}$ in the cultivation medium. In case of repeated DTT addition a first pulse of 0.65 M DTT stock solution (in MSM) was added to the culture 2 hours after RI induction to achieve final DTT concentration of $12 \mathrm{mM}$. Additionally two pulses of each $6 \mathrm{mM}$ DTT (final concentration) were added after each of the two following hours.

At the first DTT addition point the air flow was reduced from 30 to 3-4 $\mathrm{L} \mathrm{min}^{-1}$ and stirring was manually regulated to maintain an oxygen concentration of about $0 \%$ in the culture in the presence of DTT (as in [13]). The glucose feeding rate during the fed-batch cultures was controlled by the Biostat software (version 4.62). All processes were monitored by the MFCS/win 2.0 supervisory system. Exponential feeding profiles were programmed to maintain a specific growth rate of $\mu \approx 0.22 \mathrm{~h}^{-1}$ as earlier described [13].

The fed-batch cultivations were started with a volume of $8.0 \mathrm{~L}$ of MSM, and containing 8 or $15 \mathrm{~g} \mathrm{~L}^{-1}$ of glucose, respectively. The fed-batch mode was started after the initial batch cultivation at $\mathrm{OD}_{600} \approx 9.5$ or $\mathrm{OD}_{600} \approx$ 18 , respectively. GroELS were induced 1 hour before RI induction at $\mathrm{OD}_{600} \approx 12.5-14$ or $\mathrm{OD}_{600} \approx 24-26$ in both cases respectively at a specific growth rate $\mu=0.22 \pm$ $0.02 \mathrm{~h}^{-1}$ under glucose limitation. RI induction during the fed-batch cultures was peformed with $0.2 \mathrm{mM}$ IPTG at $\mathrm{OD}_{600} \approx 18$ or $\mathrm{OD}_{600} \approx 38\left(\mu=0.22 \pm 0.02 \mathrm{~h}^{-1}\right)$ and the temperature was shifted to $22^{\circ} \mathrm{C}$. The cultures were continued for 5 hours.

The batch cultures were performed in $8 \mathrm{~L}$ of MSM medium with $15 \mathrm{~g} \mathrm{~L}^{-1}$ of glucose. The induction of GroELS at the batch cultivation mode was performed at $\mathrm{OD}_{600}=3.0$ with $0.4 \mathrm{~g} \mathrm{~L}^{-1}$ of arabinose. RI induction with $0.2 \mathrm{mM}$ IPTG was performed one hour later at an $\mathrm{OD}_{600}$ of $6.0\left(\mu \approx 0.5 \mathrm{~h}^{-1}\right)$ and the temperature was shifted to $22^{\circ} \mathrm{C}$. After RI induction the cultures were continued for 5 hours.

\section{Analytical tools}

Cell samples harvested from flask and bioreactor cultivations were resuspended in lysis buffer at the following ratio: $1 \mathrm{~g}$ of biomass were resuspended in $10 \mathrm{~mL}$ of lysis buffer (50 mM Tris- $\mathrm{H}_{3} \mathrm{PO}_{4} \mathrm{pH}$ 8.0, 0.1\% Triton X-100, $2 \mathrm{mM}$ EDTA, $1 \mathrm{mM}$ PMSF, $12 \mathrm{mM}$ DTT, 10\% propyleneglycol, $0.1 \mathrm{mg} \mathrm{mL}^{-1}$ lysozyme). After $30 \mathrm{~min}$ of incubation at $+4^{\circ} \mathrm{C}$ the biomass was sonicated for $60 \mathrm{sec}$ (Vibra cell ${ }^{\mathrm{TM}}$, Sonic and Materials Inc., sonotrode $6 \mathrm{~mm}$ diameter, amplitude $50 \%$ ) at $4{ }^{\circ} \mathrm{C}$. Soluble and insoluble protein fractions were separated by centrifugation for 30 $\min , 14000 \mathrm{rpm}, 4^{\circ} \mathrm{C}$. The total protein fraction represents cellular debris suspension (crude extract) before 
centrifugation. After centrifugation the insoluble protein pellet was additionally washed and resuspended in the original volume of lysis buffer without lysozyme.

Samples for SDS-PAGE separation were prepared as folllows: $20 \mu \mathrm{L}$ of protein sample (total soluble, insoluble, protein suspensions), $25 \mu \mathrm{L}$ of $4 \times$ SDS-PAGE loading buffer (Fermentas), $5 \mu \mathrm{L}$ of $20 \times$ DTT (Fermentas) and $50 \mu \mathrm{L}$ of deionized water to obtain a final sample volume of $100 \mu \mathrm{L}$. Samples were heated for $15 \mathrm{~min}$ at $95^{\circ} \mathrm{C} .10 \mu \mathrm{L}$ of sample was applied to each lane of a $10 \%$ SDS-PAGE gel.

The amounts in mg of target RI were determined from scanned SDS-PAGE gel images by analysis of the images with TotalLab Quant software (Totallab, Newcaslte, Great Britain). The gels with separated sample proteins were produced for TotalLab quantifications with BSA standards in 3 concentrations on each gel.

The amount of active RI in the soluble protein fraction was determined by an activity assay described by Blackburn et al. [29,30]. One mg of native RI correlates with an activity of about $\sim 100 \mathrm{kU}$ as described by Blackburn et al. [30].

The amount of oxidized/reduced DTT in the cultivation medium was determined by using the MeasureiT ${ }^{\mathrm{TM}}$ Thiol Assay kit (Invitrogen) according to the recommendations of the supplier.

\section{Additional material}

Additional file 1: SDS-PAGE images of total cell extracts (T), soluble (S), or insoluble (IN) protein fractions normalised to equal cell amounts of E. coli ER2566 pET21bRI after 4 hours of batch RI production with addition of $12 \mathrm{mM}$ DTT at the time of RI induction (gels marked with triangles - B, E), 2 hours after RI induction (gels marked with squares - C, F), or no addition of DTT (A, D),

respectively. Batch shake flask cultures were performed in glucose MSM at 37 (gel images: A-C), or $22^{\circ} \mathrm{C}$ (gel images: D-F). Lane abbreviations: $1 T$ - total protein fraction 10 min before induction, 2 (S), 3 (T) and 4 (IN) soluble, total and insoluble protein fractions 4 hours after RI induction. Protein size marker: PageRuler ${ }^{\mathrm{TM}}{ }^{\mathrm{TM}}$ Protein Ladder Plus (Fermentas).

Additional file 2: SDS-PAGE images of total cell extracts (T), soluble (S), or insoluble (IN) protein fractions normalised to equal cell amounts of $E$. coli ER2566 pET21bRI pKJE7 after 4 hours of batch RI production with addition of $12 \mathrm{mM}$ DTT at the time of RI induction (gels marked with triangles - B, E), 2 hours after RI induction (gels marked with squares - C, F), or no addition of DTT (A, D), respectively. For explanations see Additional file 1 .

Additional file 3: SDS-PAGE images of total cell extracts (T), soluble (S), or insoluble (IN) protein fractions of E. coli ER2566 pET21bRI pGro7 normalized to equal cell amounts after 4 hours of batch RI production with addition of $12 \mathrm{mM}$ DTT at the time of RI induction (marked with triangles $-\mathrm{B}, \mathrm{E}, \mathrm{H}$ ), 2 hours after RI induction (marked with squares-C, $F, I)$, or no addition of DTT $(A, D, G)$, respectively. Batch shake flask cultures were performed in glucose MSM at 37 (gel images: A-C), 30 (gel images: D-F), or $22^{\circ} \mathrm{C}$ (gel images: G-I). For further explanations see Additional file 1

Additional file 4: SDS-PAGE images of total cell extracts (T), soluble (S), or insoluble (IN) protein fractions from EnBase fed-batch cultures of $E$. coli ER2566 pET21bRI pGro7 normalized to equal cell amounts after 4 hours of RI production without (A) or with addition of $12 \mathrm{mM}$ DTT (B). Rl was induced at $\mathrm{OD}_{600}$ of 11. For further explanations see Additional file 1.

Additional file 5: SDS-PAGE images of total cell extracts (T), soluble (S), or insoluble (IN) protein fractions from batch and fed-batch bioreactor cultures of $E$. coli ER2566 pET21bRI pGro7 normalized to equal cell amounts after 4 hours of RI production without (A) or with addition of DTT (B). Gels A and B: protein fractions after RI batch production without (A) and with a single addition of $12 \mathrm{mM}$ DTT (B) added 2 hours after RI induction. Gels $C$ and D: protein fractions after a fed-batch process without (C) and with repeated addition of DTT (D) the first DTT pulse (12 mM ) added 2 hours after RI induction. For further explanations see Additional file 1 .

\section{Acknowledgements}

The work was performed in relation with the UNICAT Center of Excellence at the TU Berlin. The research project was fiancially supported by a research grant of Fermentas UAB belonging to Thermo Fisher Scientific Inc.

\section{Author details}

${ }^{1}$ Thermo Fisher Scientific (formerly Fermentas), V.Graiciuno 8, LT-02241 Vilnius, Lithuania. ${ }^{2}$ Chair of Bioprocess Engineering, Department of Biotechnology, Technische Universität Berlin, Ackerstr. 71-76, D-13355 Berlin, Germany.

\section{Authors' contributions}

JS designed the experimental setup, performed all cultivation experiments and prepared the manuscript. PN initiated the project, assisted with data analysis and manuscript preparation. Both authors read and approved the final manuscript.

\section{Competing interests}

The authors declare that they have no competing interests.

Received: 19 March 2011 Accepted: 8 August 2011

Published: 8 August 2011

\section{References}

1. Makino T, Skretas G, Georgiou G: Strain engineering for improved expression of recombinant proteins in bacteria. Microb Cell Fact 2011, 10:32.

2. Correa A, Oppezzo P: Tuning different expression parameters to achieve soluble recombinant proteins in E. coli: Advantages of high-throughput screening. Biotechnol J 2011.

3. Samuelson JC: Recent developments in difficult protein expression: a guide to E. coli strains, promoters, and relevant host mutations. Methods Mol Biol 2011, 705:195-209.

4. Lizak C, Fan YY, Weber TC, Aebi M: N-Linked glycosylation of antibody fragments in Escherichia coli. Bioconjug Chem 2011, 22:488-496.

5. Schwarz F, Huang W, Li C, Schulz BL, Lizak C, Palumbo A, Numao S, Neri D, Aebi M, Wang LX: A combined method for producing homogeneous glycoproteins with eukaryotic N-glycosylation. Nat Chem Biol 2010, 6:264-266

6. Gregersen N, Bross P: Protein misfolding and cellular stress: an overview. Methods Mol Biol 2010, 648:3-23.

7. Mohammadian-Mosaabadi J, Naderi-Manesh H, Maghsoudi N, Khalilzadeh R, Shojaosadati SA, Ebrahimi M: Effect of oxidative stress on the production of recombinant human interferon-gamma in Escherichia coli. Biotechnol Appl Biochem 2005, 41:37-42.

8. Dickson KA, Haigis MC, Raines RT: Ribonuclease inhibitor: structure and function. Prog Nucleic Acid Res Mol Biol 2005, 80:349-374.

9. Kobe $B$, Kajava $A V$ : The leucine-rich repeat as a protein recognition motif. Curr Opin Struct Biol 2001, 11:725-732.

10. Klink TA, Vicentini AM, Hofsteenge J, Raines RT: High-level soluble production and characterization of porcine ribonuclease inhibitor. Protein Expr Purif 2001, 22:174-179

11. Lee FS, Vallee BL: Expression of human placental ribonuclease inhibitor in Escherichia coli. Biochem Biophys Res Commun 1989, 160:115-120. 
12. Vicentini AM, Kieffer B, Matthies R, Meyhack B, Hemmings BA, Stone SR, Hofsteenge J: Protein chemical and kinetic characterization of recombinant porcine ribonuclease inhibitor expressed in Saccharomyces cerevisiae. Biochemistry 1990, 29:8827-8834.

13. Šiurkus J, Panula-Perälä J, Horn U, Kraft M, Rimseliene R, Neubauer P: Novel approach of high cell density recombinant bioprocess development: optimisation and scale-up from microliter to pilot scales while maintaining the fed-batch cultivation mode of E. coli cultures. Microb Cell Fact 2010, 9:35.

14. Guo W, Cao L, Jia Z, Wu G, Li T, Lu F, Lu Z: High level soluble production of functional ribonuclease inhibitor in Escherichia coli by fusing it to soluble partners. Protein Expr Purif 2011, 77:185-192.

15. Šiurkus J, Neubauer P: Reducing conditions are the key for efficient production of active ribonuclease inhibitor in Escherichia coli. Microb Cell Fact 2011, 10.

16. Panula-Perälä J, Šiurkus J, Vasala A, Wilmanowski R, Casteleijn MG, Neubauer P: Enzyme controlled glucose auto-delivery for high cell density cultivations in microplates and shake flasks. Microb Cell Fact 2008, 7:31.

17. Kolaj O, Spada S, Robin S, Wall JG: Use of folding modulators to improve heterologous protein production in Escherichia coli. Microb Cell Fact 2009, 8:9.

18. Yokoyama K, Kikuchi Y, Yasueda H: Overproduction of DnaJ in Escherichia coli improves in vivo solubility of the recombinant fish-derived transglutaminase. Biosci Biotechnol Biochem 1998, 62:1205-1210.

19. Han KG, Lee SS, Kang C: Soluble expression of cloned phage K11 RNA polymerase gene in Escherichia coli at a low temperature. Protein Expr Purif 1999, 16:103-108.

20. Zhang Z, Li ZH, Wang F, Fang M, Yin CC, Zhou ZY, Lin Q, Huang HL: Overexpression of DsbC and DsbG markedly improves soluble and functional expression of single-chain Fv antibodies in Escherichia coli. Protein Expr Purif 2002, 26:218-228.

21. Hu X, O'Hara L, White S, Magner E, Kane M, Wall JG: Optimisation of production of a domoic acid-binding ScFv antibody fragment in Escherichia coli using molecular chaperones and functional immobilisation on a mesoporous silicate support. Protein Expr Purif 2007, 52:194-201.

22. Hoffmann F, Rinas U: Stress induced by recombinant protein production in Escherichia coli. Adv Biochem Eng Biotechnol 2004, 89:73-92.

23. Jürgen B, Lin HY, Riemschneider S, Scharf C, Neubauer P, Schmid R, Hecker M Schweder T: Monitoring of genes that respond to overproduction of an insoluble recombinant protein in Escherichia coli glucose-limited fed-batch fermentations. Biotechnol Bioeng 2000, 70:217-224.

24. Goff SA, Goldberg AL: Production of abnormal proteins in E. coll stimulates transcription of lon and other heat shock genes. Cell 1985, 41:587-595.

25. Hoffmann F, Weber J, Rinas U: Metabolic adaptation of Escherichia coli during temperature-induced recombinant protein production: 1. Readjustment of metabolic enzyme synthesis. Biotechnol Bioeng 2002, 80:313-319.

26. Neubauer $P$, Lin HY, Mathiszik B: Metabolic load of recombinant protein production: inhibition of cellular capacities for glucose uptake and respiration after induction of a heterologous gene in Escherichia coli. Biotechnol Bioeng 2003, 83:53-64.

27. Dong H, Nilsson L, Kurland CG: Gratuitous overexpression of genes in Escherichia coli leads to growth inhibition and ribosome destruction. J Bacteriol 1995, 177:1497-1504.

28. Lin HY, Hanschke R, Nicklisch S, Nietsche T, Jarchow R, Schwahn C, Riemschneider S, Meyer S, Gupta A, Hecker M, Neubauer P: Cellular responses to strong overexpression of recombinant genes in Escherichia coli DNA relaxation and cell death after induction of a-glucosidase. In Recombinant Protein Production with prokaryotic and eukaryotic cells. A comparative view on host physiology edition. Edited by: Merten OW, Mattanovich D, Lang C, Larsson G, Neubauer P, Porro D et al. Dortrecht: Kluwer Academic Publisher; 2001:55-74.

29. Blackburn $P$, Wilson $G$, Moore $S$ : Ribonuclease inhibitor from human placenta. Purification and properties. J Biol Chem 1977, 252:5904-5910

30. Blackburn P: Ribonuclease inhibitor from human placenta: rapid purification and assay. J Biol Chem 1979, 254:12484-12487.

doi:10.1186/1475-2859-10-65

Cite this article as: Šiurkus and Neubauer: Heterologous production of active ribonuclease inhibitor in Escherichia coli by redox state control and chaperonin coexpression. Microbial Cell Factories 2011 10:65.

\section{Submit your next manuscript to BioMed Central and take full advantage of:}

- Convenient online submission

- Thorough peer review

- No space constraints or color figure charges

- Immediate publication on acceptance

- Inclusion in PubMed, CAS, Scopus and Google Scholar

- Research which is freely available for redistribution

Submit your manuscript at www.biomedcentral.com/submit 